\title{
Editorial
}

Ophthalmologe $2020 \cdot 117: 295$

https://doi.org/10.1007/s00347-020-01097-3

Online publiziert: 30 . März 2020

(c) Springer Medizin Verlag GmbH, ein Teil von Springer Nature 2020

Liebe Kolleginnen und Kollegen,

die SARS-CoV-2-Pandemie stellt eine epochale Herausforderung dar. Obwohl es Hinweise gibt, dass das Virus weniger wahrscheinlich letale Komplikationen im Vergleich zu SARS-Coronavirus oder MERS-Coronavirus mit sich bringt, steigt die Zahl der Betroffenen dramatisch an. Bislang gibt es keinen Impfstoff, um die Infektion präventiv zu verhindern, und auch keine Therapie gegen das Virus.

Patienten zeigen initial typischerweise Zeichen einer Atemwegserkrankung, schließlich Fieber, Husten und Kurzatmigkeit. Konjunktivitis wurde ebenfalls beschrieben. Symptome können bereits nach zwei Tagen, aber auch erst nach 14 Tagen nach Exposition auftreten. Wenngleich Tröpfcheninfektion und direkter Kontakt nachgewiesenermaßen die Hauptübertragungswege der Infektion sind, könnten auch Konjunktiven eine Eingangspforte für das Virus sein. Möglicherweise wird SARS-CoV-2 auch durch Aerosolkontakt mit der Konjunktiva übertragen $[1,2]$.

Der Augenarzt, Dr. Li Wenliang, war in China einer der ersten, der auf eine „SARS-ähnliche“ Epidemie hinwies. Er selbst hat sich an einem asymptomatischen Glaukom-Patienten infiziert und ist an Komplikationen der Erkrankung verstorben [3].

Insbesondere in der Augenheilkunde können und müssen wir dazu beitragen, die Ausbreitung des Virus einzugrenzen, denn die Infektion bedroht in besonderem Ausmaß den Großteil unserer Patienten: alte und kranke Menschen. Die Versorgung muss vorübergehend in allen Bereichen auf Notfälle und Notfalleingriffe zurückgefahren werden. Unabhängig hiervon sind immer individuelle

Frank G. Holz

Universitäts-Augenklinik Bonn, Bonn, Deutschland

\section{SARS-CoV-2: Herausforderung für alle}

Abwägungen erforderlich, um dem Ziel des Patientenwohls gerecht zu werden. Die IVOM-Therapie sollte in der Regel fortgeführt werden, da sonst irreversibler Sehverlust droht. Allerdings unter Beachtung zusätzlicher Kautelen, wie Vorkehrung in Wartebereichen mit ausreichendem Abstand sowie Reduktion der Frequenz, Verlängerung der Sprechzeiten und Minimierung bei der Befunderhebung. Letztlich sind wir alle dazu aufgefordert, Prozesse dahingehend kritisch zu hinterfragen und Sicherheitsvorkehrungen zu treffen. Hierzu zählen auch weitere einschneidende Maßnahmen wie Besuchsverbote in Kliniken und Begleitpersonen in Praxen und Kliniken zu bitten, außerhalb auf ihre Angehörigen zu warten. Spezifisch augenärztliche Maßnahmen umfassen auch einfache pragmatische Lösungen wie das Anbringen von Schutzfolien an Spaltlampen. Diese Maßnahmen ersetzen gleichwohl nicht die ausreichende Zurverfügungstellung von Schutzkleidung und adäquaten Masken. Hilfreich könnte in dieser Phase auch der vorübergehende Einsatz von telemedizinischen Ansätzen zur direkten Kontaktvermeidung sein.

Wie lange all diese drastischen Maßnahmen noch erforderlich sein werden, ist im Moment nicht abzusehen. Viele Vorhersagen beruhen derzeit auf Annahmen. Es ist ein sehr dynamischer Prozess, der in vielen tagesaktuellen Darstellungen wiedergegeben wird. Auch wird auch von einem relevanten Underrreporting Infizierter, aber symptomfreier/-armer, nicht getesteter, und damit nicht gemeldeter Fälle ausgegangen. Internationale Schätzungen zum Underreporting liegen bei einem Faktor um 10 und teilweise sogar darüber. Entsprechend könnte auch für Deutschland die Herdenim- munität früher erreicht werden als momentan prognostiziert.

Wir sind jetzt alle gefragt, unseren verantwortlichen Beitrag zu leisten. Genau das werden wir tun.

Frank G. Holz

Verfasst am: 25.03.2020

\section{Korrespondenzadresse}

Prof. Dr. Frank G. Holz

Universitäts-Augenklinik Bonn

Ernst-Abbe-Str. 2, 53127 Bonn, Deutschland

Frank.Holz@ukbonn.de

\section{Literatur}

1. Jianhua Xia MM, Tong J, Mengyun Liu MM, Shen Y, Guo D (2020) Evaluation of coronavirus in tears and conjunctival secretions of patients with SARSCoV-2 infection. J Med Virol. https://doi.org/10. 1002/jmv.25725

2. The China Medical Treatment Expert Group for Covid-19, Guan W et al (2020) Clinical characteristics of Coronavirus disease 2019 in China. N Eng J Med. https://doi.org/10.1056/ NEJMoa2002032

3. Buckley C (2020) Chinese doctor, silenced after warning of outbreak, dies from Coronavirus. New York Times. 7. Februar, 2020. https://www.nytimes. com/2020/02/06/world/asia/chinese-doctor-LiWenliang-coronavirus.html 